UMTRI-2000-2

\title{
THE USE OF PARKING AND AUXILIARY LAMPS FOR TRAFFIC SIGN ILLUMINATION
}

\author{
Michael Sivak \\ Michael J. Flannagan \\ Toshio Miyokawa
}

January 2000 
THE USE OF PARKING AND AUXILIARY LAMPS FOR TRAFFIC SIGN ILLUMINATION

Michael Sivak Michael J. Flannagan

Toshio Miyokawa

The University of Michigan Transportation Research Institute Ann Arbor, Michigan 48109-2150 U.S.A.

Report No. UMTRI-2000-2

January 2000 
Technical Report Documentation Page

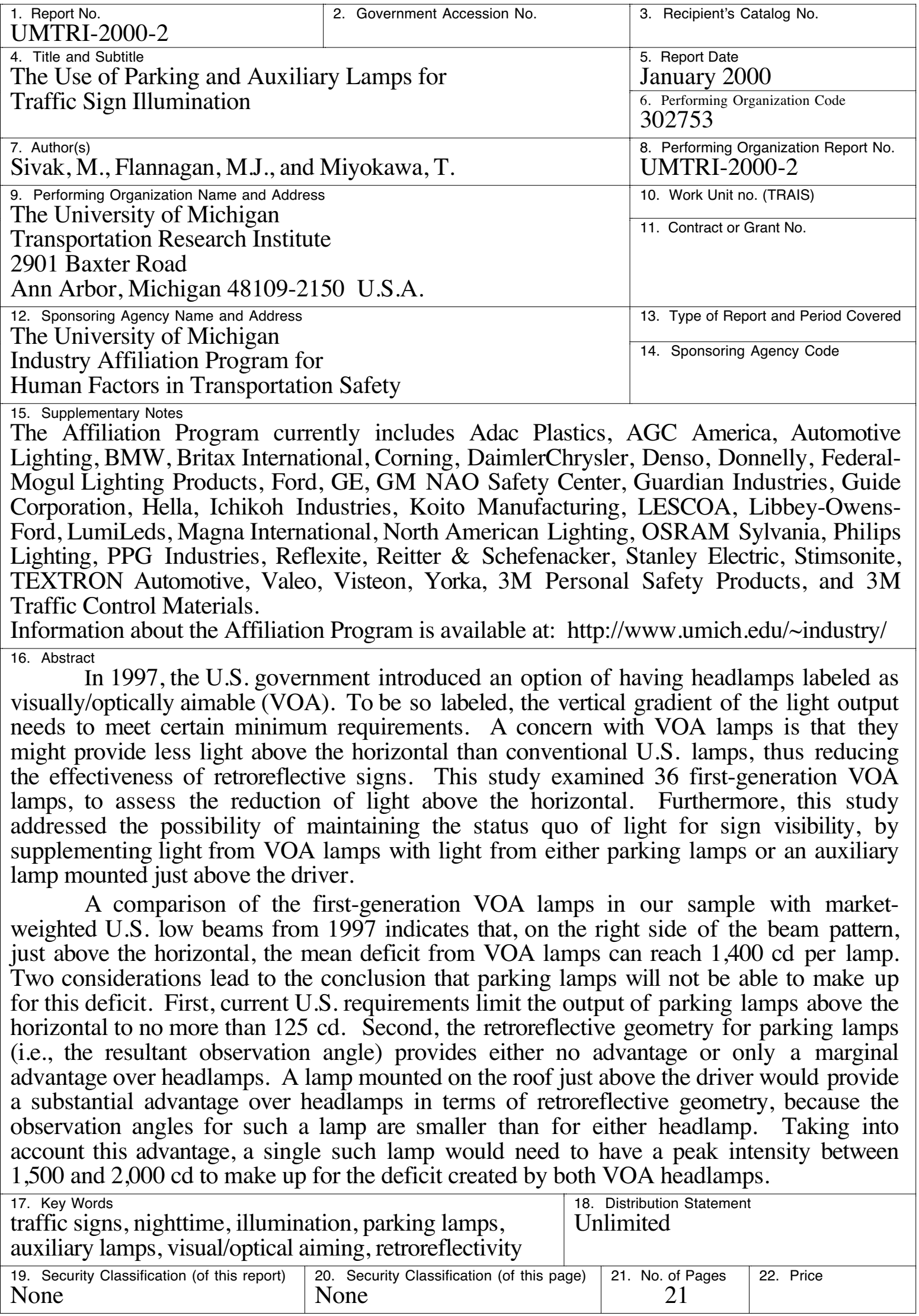




\title{
ACKNOWLEDGMENTS
}

Appreciation is extended to the members of the University of Michigan Industry Affiliation Program for Human Factors in Transportation Safety for support of this research. The current members of the Program are:

\author{
Adac Plastics \\ AGC America \\ Automotive Lighting \\ BMW \\ Britax International \\ Corning \\ DaimlerChrysler \\ Denso \\ Donnelly \\ Federal-Mogul Lighting Products \\ Ford \\ GE \\ GM NAO Safety Center \\ Guardian Industries \\ Guide Corporation \\ Hella \\ Ichikoh Industries \\ Koito Manufacturing \\ LESCOA \\ Libbey-Owens-Ford \\ LumiLeds \\ Magna International \\ North American Lighting \\ OSRAM Sylvania \\ Philips Lighting \\ PPG Industries \\ Reflexite \\ Reitter \& Schefenacker \\ Stanley Electric \\ Stimsonite \\ TEXTRON Automotive \\ Valeo \\ Visteon \\ Yorka \\ 3M Personal Safety Products \\ 3M Traffic Control Materials
}




\section{CONTENTS}

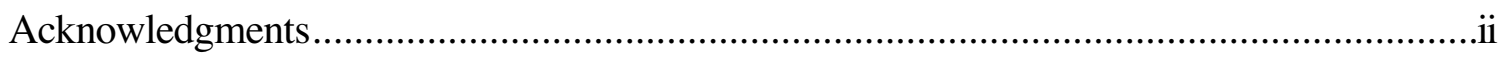

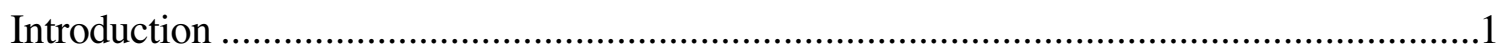

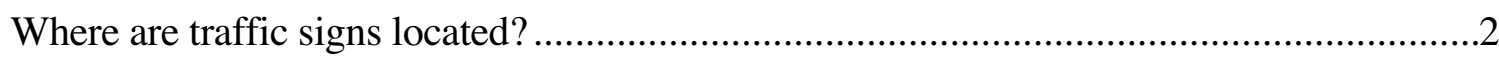

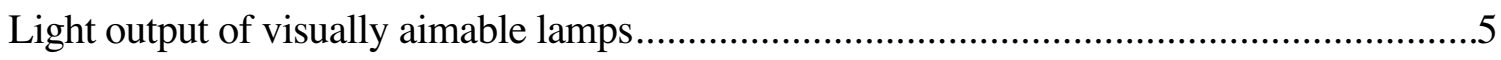

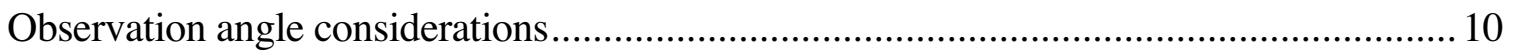

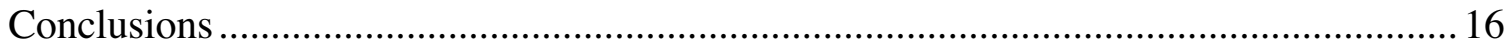

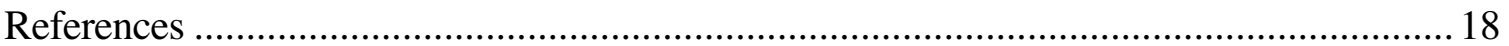




\section{INTRODUCTION}

Retroreflective traffic signs rely on headlamp illumination for their effective performance. However, in certain geometric situations, illumination needed for traffic signs can also constitute glare illumination for oncoming traffic. Therefore, traffic-sign needs always had to be balanced with glare concerns. Relatively speaking, the resulting balance in the U.S. tend to favor traffic signs, while in Europe glare protection.

In 1997, the U.S. government (FMVSS, 1997) introduced an option of having lamps labeled as visually/optically aimable (VOA). To be so labeled, the vertical gradient of the light output needs to meet certain minimum requirements, either to the left of the vertical (VOL) or to the right of the vertical (VOR). Although both VOL and VOR lamps have steeper vertical gradients than conventional U.S. lamps, VOL lamps are conceptually similar to standard European lamps, while VOR lamps are more akin to conventional U.S. lamps.

One concern with VOA lamps is that a steeper vertical gradient could be achieved by less light above the horizontal (as opposed to more light below the horizontal). If, indeed, VOA lamps provide less light above the horizontal than do conventional U.S. lamps, then the effectiveness of retroreflective signs is reduced.

One way of having the cake and being able to eat it too, would be to supplement the light above the horizontal from VOA lamps with light from parking lamps or from auxiliary lamps mounted just above the driver (e.g., on the roof of a vehicle). This report explores the possibility of such an approach to maintaining the status quo in the U.S. of sign performance.

The overall approach involved addressing the following issues:

(1) Where are traffic signs located?

(2) How much less light do visually aimable lamps deliver to the areas where signs are?

(3) How do the sensitivity to observation angle of retroreflective materials and the differences in observation angles for headlamps, parking lamps, and auxiliary lamps, influence the amount of light that would need to be added to the VOA headlamps? 


\section{WHERE ARE TRAFFIC SIGNS LOCATED?}

Traffic signs can be located off to the right of the rightmost lane, off to the left of the leftmost lane, and above the road itself. The signs can be positioned on straight portions of roadways, lateral curves, or vertical curves. Furthermore, the distances at which signs are of relevance span a considerable range. For example, at high speeds it might be important to detect signs at distances exceeding $300 \mathrm{~m}$, while at low speeds the relevant legibility distances might be shorter than $50 \mathrm{~m}$. Consequently, traffic signs can occupy a wide range of angular locations with respect to the axis of a headlamp.

\section{Analytical derivations}

Sivak, Gellatly, and Flannagan (1991) calculated the angular coordinates of signs with respect to both the left and right headlamps for a variety of conditions. Three sign positions were considered: on the right shoulder, directly overhead, and on the left shoulder of a two-lane roadway (see Figure 1).

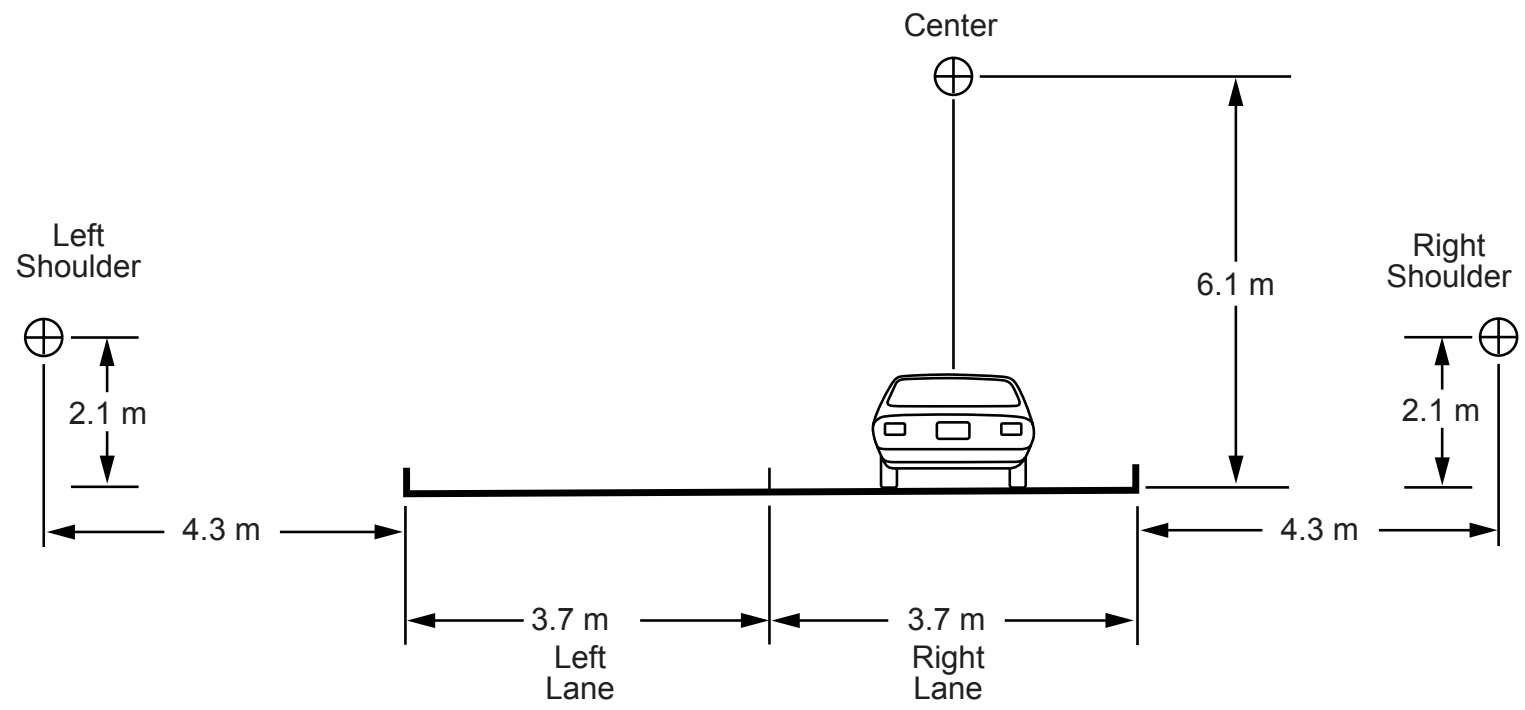

Figure 1. The sign positions in Sivak, Gellatly, and Flannagan (1991). 
The road geometry included straight portions, left and right curves with radii of $610 \mathrm{~m}$, and hills and sags with radii of 1,830 m. There were six headlamp-to-sign distances, in 61-m steps, ranging from 366 to $61 \mathrm{~m}$. The headlamps were assumed to be mounted 69 $\mathrm{cm}$ above the ground, with the lateral separation between the left and right lamps of $152 \mathrm{~cm}$. Figure 2 presents a summary of the results, combined for all sign positions, and road geometries, and for both lamps. The information in Figure 2 indicates that for the conditions studied, the relevant horizontal angles ranged from about $19^{\circ}$ left to $19^{\circ}$ right, and the relevant vertical angles above the horizontal extended all the way to about $7^{\circ}$. (Sivak, Gellatly, and Flannagan [1991] did not consider combinations that involved simultaneous lateral and vertical curvatures of the roadway. If they had, the empty regions in the upper left and upper right corners of Figure 2 would be filled with sign positions. However, simultaneous lateral and vertical curvatures are likely to be less frequent than either lateral or vertical curvatures alone.)

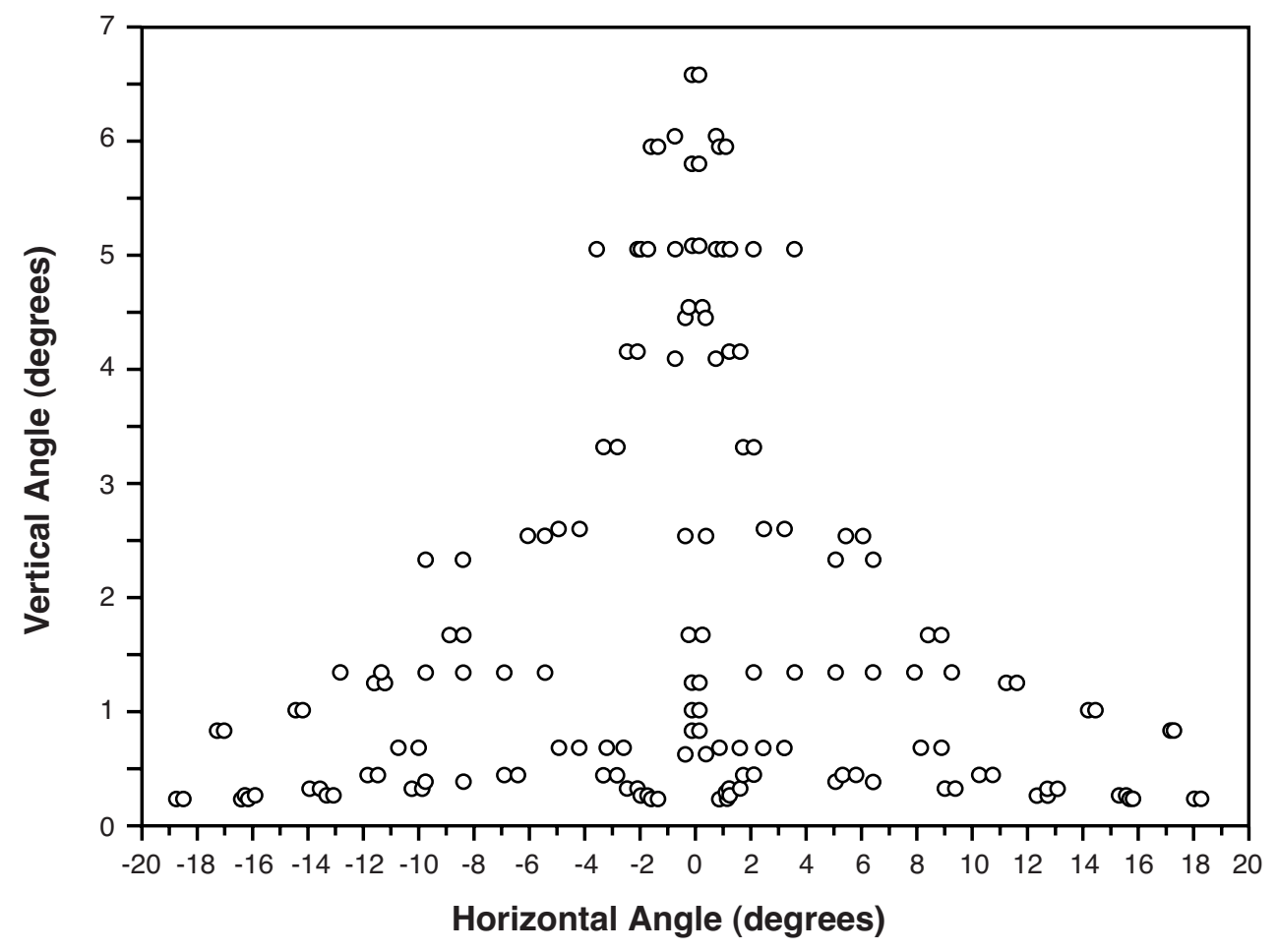

Figure 2. The locations of traffic signs with respect to the left and right headlamps for a variety of roadway conditions, sign positions, and distances. For clarity, the vertical axis is expanded in relation to the horizontal axis. (Adapted from Sivak, Gellatly, and Flannagan, 1991.) 


\section{Field measurements}

Damasky's (1995) dissertation contains the most extensive field data available on the angular coordinates of traffic signs with respect to a hypothetical headlamp mounted at the vehicle centerline and $65 \mathrm{~cm}$ above the ground. Damasky obtained his data by traversing 5,500 $\mathrm{km}$ of roads in Germany and recording all signs that were encountered. The data are presented as percentile contours of angular coordinates by sign position, road type, and distance. The results indicate that, for example, the $90^{\text {th }}$ percentile contour for right shoulder mounted signs on limited access highways at a distance of $100 \mathrm{~m}$ was of an ellipsoidal shape, extending from about the vertical to $9^{\circ}$ right, and from about the horizontal to about $2^{\circ}$ up. In comparison, the $90^{\text {th }}$ percentile contour for the same signs on the same roadways, but at $50 \mathrm{~m}$, extended all the way to about $17^{\circ}$ right and $4^{\circ}$ up. On the other hand, the $90^{\text {th }}$ percentile contour for the same signs and same distance, but on rural roads, extended from about $3^{\circ}$ left to $10^{\circ}$ right, and from about $1^{\circ}$ up to about $4^{\circ}$ up. Finally, the

$90^{\text {th }}$ percentile contour for overhead signs on limited access roadways at $100 \mathrm{~m}$ extended from about $5^{\circ}$ left to $6^{\circ}$ right, and from about $2^{\circ}$ up to $6^{\circ}$ up.

\section{Summary}

Because of varied sign positions, sign distances, and road geometry, traffic signs can occupy a wide range of angles with respect to headlamps. Based on the calculated locations from Sivak et al. (1991) and field measurements of Damasky (1995), the relevant locations of signs can exceed $18^{\circ}$ left or right and $6^{\circ}$ up. In this study, we examined the region from $20^{\circ}$ left and to $20^{\circ}$ right, and from $0.5^{\circ}$ up to $5^{\circ}$ up. 


\section{LIGHT OUTPUT OF VISUALLY AIMABLE LAMPS}

\section{Sample}

Candela matrices of light output were obtained from 36 lamps that were produced by 8 different lamp manufacturers from North America, Europe, and Japan. The breakdown of the lamps by VOL and VOR, and by the type of the light source is shown in Table 1. The 36 lamps were manufactured for 23 different vehicles. (There were 13 pairs of left and right lamps manufactured for 13 different vehicles, and 10 additional lamps manufactured for 10 different vehicles.) These lamps are the same VOA lamps that were originally described by Sivak, Flannagan, and Miyokawa (2000).

Table 1

The breakdown of lamps by VOL and VOR, and by the type of the light source.

\begin{tabular}{|l|c|c|c|}
\hline \multicolumn{1}{|c|}{ Light source } & VOL & VOR & Total \\
\hline \hline 9006 & 14 & 10 & 24 \\
\hline 9007 & 0 & 5 & 5 \\
\hline H4 & 2 & 0 & 2 \\
\hline H7 & 1 & 0 & 1 \\
\hline HID & 4 & 0 & 4 \\
\hline \hline Total & 21 & 15 & 36 \\
\hline
\end{tabular}

The photometry for 33 lamps was provided to us by the manufacturers themselves, in response to our request for VOA lamps. Three additional lamps were purchased by us as VOA lamps, and they were photometered especially for this study. (Compliance with the requirements for visually aimable lamps was not independently verified.)

The examined portion of the photometry matrices extended from $20^{\circ}$ left to $20^{\circ}$ right, and from $0.5^{\circ}$ up to $5^{\circ}$ up, all in $0.5^{\circ}$ steps. The photometry was performed at $12.8 \mathrm{~V}$. The analysis to follow uses the mean data for the VOL, and the mean data for the VOR lamps. 


\section{Comparison of visually aimable lamps to conventional lamps}

The VOA lamps in the present sample were compared to conventional U.S. lamps that were manufactured prior to the introduction of VOA lamps. Specifically, we used a market-weighted median U.S. beam pattern for the 1997 model year (Sivak, Flannagan, Kojima, and Traube, 1997) as the comparison sample. The analyses were performed separately for VOL and VOR lamps, because these two types of lamps have the sharpest vertical gradient in different parts of the beam pattern, and thus their beam patterns are substantially different.

\section{Percent changes}

Human visual sensitivity is more closely related to percent changes in illumination than to absolute changes. For example, to detect a change in the intensity of a stimulus, the intensity needs to be increased by about $25 \%$ regardless of the baseline value (e.g., Huey, Decker, and Lyons, 1994; Sayer, Flannagan, Sivak, Kojima, and Flannagan, 1997). In other words, a small absolute change might be detectable for a weak baseline stimulus (if the change reaches at least 25\%), but the same change (in absolute terms) might not be detectable for a strong stimulus (if it fails to reach 25\%). Consequently, $25 \%$ is frequently used as an approximate benchmark for whether a change in a photometric value matters.

Following this logic, we computed the percent changes from the baseline of the current light output to either the VOL or VOR lamps, to identify regions where there might be decrements in output that might matter. Figures 3 and 4 present the results of these analyses. Each of these two figures contains three separately coded regions of the beam pattern:

- regions where VOA lamps direct more light than conventional lamps;

- regions where VOA lamps direct less light than conventional lamps, but the change is less than $25 \%$; and

- regions where VOA lamps direct less light than conventional lamps, and the change is at least $25 \%$.

The information in Figure 3 indicates that for the VOL lamps, decrements of $25 \%$ or more were confined to an area from $6.5^{\circ}$ left to $10^{\circ}$ right, and from $0.5^{\circ}$ up to $3^{\circ}$ up. In contrast, for the VOR lamps decrements of $25 \%$ or more extended from $2^{\circ}$ left to $20^{\circ}$ right, and from $0.5^{\circ}$ up to $5^{\circ}$ up. In other words, for the VOR lamps the substantial decrements were more to the right and up, as compared to the VOL lamps. 


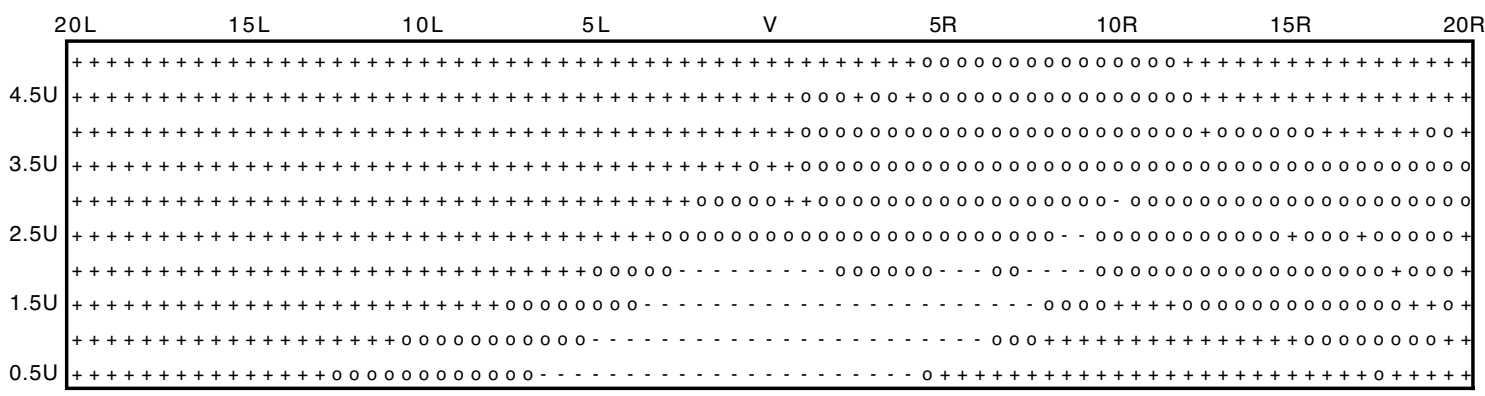

Figure 3. Percent changes in the light output of the VOL lamps, compared to the conventional U.S. lamps. (+: the VOL lamps produce more light than the conventional lamps; 0: the VOL lamps produce less light than the conventional lamps, but the difference is less than 25\%; -: the VOL lamps produce less light than the conventional lamps, and the difference is at least $25 \%$ )

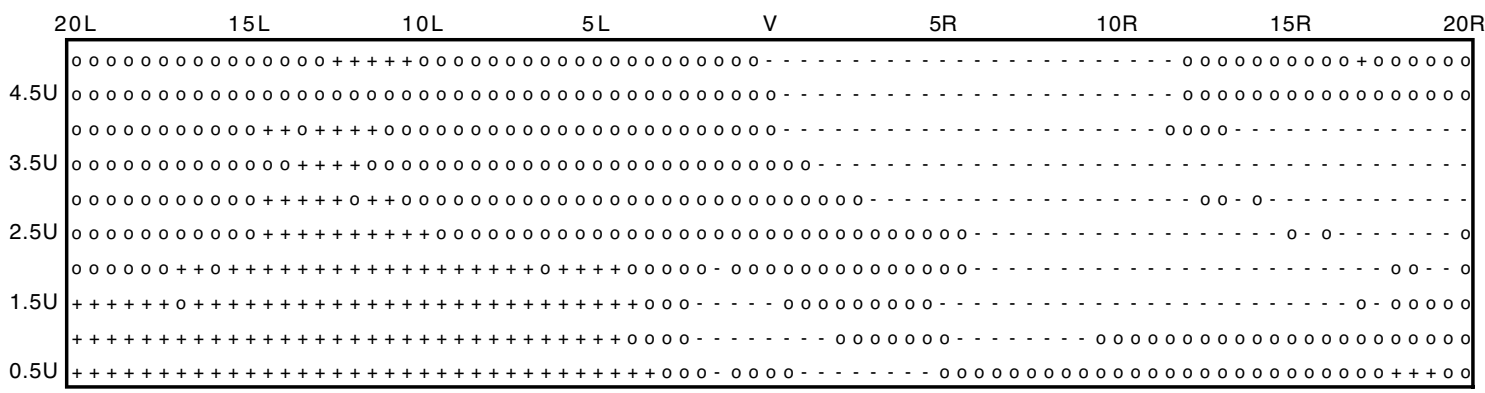

Figure 4. Percent changes in the light output of the VOR lamps, compared to the conventional U.S. lamps. (+: the VOR lamps produce more light than the conventional lamps; 0: the VOR lamps produce less light than the conventional lamps, but the difference is less than 25\%; -: the VOR lamps produce less light than the conventional lamps, and the difference is at least $25 \%$ ) 


\section{Absolute changes}

For the areas in Figures 3 and 4, in which the decrements in the light output were at least $25 \%$, Tables 2 and 3 present the absolute decrements.

Table 2

Decrements in the light output (in cd) of the VOL lamps compared to the conventional U.S. lamps, for regions where the decrements are at least $25 \%$.

\begin{tabular}{|l||c|c|c|c|c|c|c|c|c|c|c|c|c|c|c|}
\hline & $6.5 \mathrm{~L}$ & $6 \mathrm{~L}$ & $5.5 \mathrm{~L}$ & $5 \mathrm{~L}$ & $4.5 \mathrm{~L}$ & $4 \mathrm{~L}$ & $3.5 \mathrm{~L}$ & $3 \mathrm{~L}$ & $2.5 \mathrm{~L}$ & $2 \mathrm{~L}$ & $1.5 \mathrm{~L}$ & $1 \mathrm{~L}$ & $0.5 \mathrm{~L}$ & 0 & $0.5 \mathrm{R}$ \\
\hline \hline $3 \mathrm{U}$ & & & & & & & & & & & & & & & \\
\hline $2.5 \mathrm{U}$ & & & & & & & & & & & & & & & \\
\hline $2 \mathrm{U}$ & & & & & & & & & 73 & 77 & 98 & 100 & 101 & 96 & 109 \\
\hline $1.5 \mathrm{U}$ & & & & & & & 71 & 103 & 119 & 165 & 203 & 236 & 217 & 225 & 235 \\
\hline $1 \mathrm{U}$ & & & & 78 & 99 & 133 & 152 & 155 & 225 & 266 & 316 & 358 & 429 & 494 & 653 \\
\hline $0.5 \mathrm{U}$ & 103 & 118 & 145 & 185 & 208 & 222 & 223 & 291 & 366 & 433 & 561 & 544 & 609 & 708 & 847 \\
\hline
\end{tabular}

\begin{tabular}{|l||c|c|c|c|c|c|c|c|c|c|c|c|c|c|c|} 
& $1 \mathrm{R}$ & $1.5 \mathrm{R}$ & $2 \mathrm{R}$ & $2.5 \mathrm{R}$ & $3 \mathrm{R}$ & $3.5 \mathrm{R}$ & $4 \mathrm{R}$ & $4.5 \mathrm{R}$ & $5 \mathrm{R}$ & $5.5 \mathrm{R}$ & $6 \mathrm{R}$ & $6.5 \mathrm{R}$ & $7 \mathrm{R}$ & $7.5 \mathrm{R}$ & $8 \mathrm{R}$ \\
\hline \hline $3 \mathrm{U}$ & & & & & & & & & & & & & & & \\
\hline $2.5 \mathrm{U}$ & & & & & & & & & & & & & & & \\
\hline $2 \mathrm{U}$ & 111 & 101 & & & & & & & 94 & 84 & 82 & & & 76 & 72 \\
\hline $1.5 \mathrm{U}$ & 240 & 238 & 237 & 233 & 229 & 223 & 212 & 201 & 222 & 183 & 175 & 139 & 122 & 107 & \\
\hline $1 \mathrm{U}$ & 602 & 607 & 507 & 496 & 403 & 439 & 376 & 307 & 314 & 371 & 252 & & & & \\
\hline $0.5 \mathrm{U}$ & 1007 & 1019 & 1400 & 1382 & 1208 & 810 & 585 & & & & & & & & \\
\hline
\end{tabular}

\begin{tabular}{|l||c|c|c|c|}
\cline { 2 - 5 } \multicolumn{1}{l||}{} & $8.5 \mathrm{R}$ & $9 \mathrm{R}$ & $9.5 \mathrm{R}$ & $10 \mathrm{R}$ \\
\hline \hline $3 \mathrm{U}$ & & & & 46 \\
\hline $2.5 \mathrm{U}$ & 61 & 58 & & \\
\hline $2 \mathrm{U}$ & 70 & 66 & & \\
\hline $1.5 \mathrm{U}$ & & & & \\
\hline $1 \mathrm{U}$ & & & & \\
\hline $0.5 \mathrm{U}$ & & & & \\
\hline
\end{tabular}


Table 3

Decrements in the light output (in cd) of the VOR lamps compared to the conventional U.S. lamps, for regions where the decrements are at least $25 \%$.

\begin{tabular}{|l||c|c|c|c|c|c|c|c|c|c|c|c|c|c|c|}
\hline & $2 \mathrm{~L}$ & $1.5 \mathrm{~L}$ & $1 \mathrm{~L}$ & $0.5 \mathrm{~L}$ & 0 & $0.5 \mathrm{R}$ & $1 \mathrm{R}$ & $1.5 \mathrm{R}$ & $2 \mathrm{R}$ & $2.5 \mathrm{R}$ & $3 \mathrm{R}$ & $3.5 \mathrm{R}$ & $4 \mathrm{R}$ & $4.5 \mathrm{R}$ & $5 \mathrm{R}$ \\
\hline \hline $5 \mathrm{U}$ & & & & & 37 & 40 & 47 & 56 & 58 & 56 & 54 & 52 & 49 & 51 & 51 \\
\hline $4.5 \mathrm{U}$ & & & & & & 48 & 58 & 60 & 63 & 63 & 63 & 63 & 61 & 75 & 75 \\
\hline $4 \mathrm{U}$ & & & & & & 46 & 64 & 66 & 68 & 70 & 75 & 85 & 81 & 85 & 77 \\
\hline $3.5 \mathrm{U}$ & & & & & & & & 78 & 79 & 77 & 78 & 87 & 103 & 98 & 92 \\
\hline $3 \mathrm{U}$ & & & & & & & & & & & 85 & 86 & 84 & 85 & 91 \\
\hline $2.5 \mathrm{U}$ & & & & & & & & & & & & & & & \\
\hline $2 \mathrm{U}$ & & 78 & & & & & & & & & & & & & \\
\hline $1.5 \mathrm{U}$ & 112 & 142 & 169 & 135 & 123 & & & & & & & & & & 142 \\
\hline $1 \mathrm{U}$ & 134 & 172 & 195 & 234 & 278 & 413 & 321 & 298 & & & & & & & \\
\hline $0.5 \mathrm{U}$ & & 232 & & & & & 485 & 536 & 990 & 1036 & 939 & 577 & 528 & 471 & \\
\hline
\end{tabular}

\begin{tabular}{|l||c|c|c|c|c|c|c|c|c|c|c|c|c|c|c|}
\hline & $5.5 \mathrm{R}$ & $6 \mathrm{R}$ & $6.5 \mathrm{R}$ & $7 \mathrm{R}$ & $7.5 \mathrm{R}$ & $8 \mathrm{R}$ & $8.5 \mathrm{R}$ & $9 \mathrm{R}$ & $9.5 \mathrm{R}$ & $10 \mathrm{R}$ & $10.5 \mathrm{R}$ & $11 \mathrm{R}$ & $11.5 \mathrm{R}$ & $12 \mathrm{R}$ & $12.5 \mathrm{R}$ \\
\hline \hline $5 \mathrm{U}$ & 44 & 46 & 46 & 46 & 44 & 41 & 41 & 40 & 37 & 37 & 32 & 30 & 28 & & \\
\hline $4.5 \mathrm{U}$ & 63 & 58 & 56 & 57 & 52 & 48 & 44 & 45 & 44 & 40 & 38 & 36 & 29 & & \\
\hline $4 \mathrm{U}$ & 71 & 66 & 64 & 62 & 57 & 54 & 53 & 48 & 48 & 42 & 39 & 32 & & & \\
\hline $3.5 \mathrm{U}$ & 87 & 78 & 75 & 80 & 68 & 66 & 61 & 58 & 52 & 42 & 42 & 36 & 36 & 37 & 39 \\
\hline $3 \mathrm{U}$ & 87 & 87 & 83 & 77 & 65 & 62 & 63 & 60 & 57 & 61 & 59 & 51 & 47 & 40 & \\
\hline $2.5 \mathrm{U}$ & & 79 & 83 & 84 & 82 & 71 & 77 & 72 & 68 & 64 & 64 & 61 & 59 & 59 & 58 \\
\hline $2 \mathrm{U}$ & & 82 & 83 & 84 & 95 & 89 & 83 & 81 & 79 & 83 & 82 & 77 & 72 & 74 & 74 \\
\hline $1.5 \mathrm{U}$ & 125 & 142 & 127 & 131 & 133 & 134 & 124 & 110 & 102 & 92 & 86 & 85 & 84 & 90 & 87 \\
\hline $1 \mathrm{U}$ & 272 & 240 & 221 & 201 & 184 & 158 & 133 & 119 & & & & & & & \\
\hline $0.5 \mathrm{U}$ & & & & & & & & & & & & & & & \\
\hline
\end{tabular}

\begin{tabular}{|l||c|c|c|c|c|c|c|c|c|c|c|c|c|c|c|}
\hline & $13 \mathrm{R}$ & $13.5 \mathrm{R}$ & $14 \mathrm{R}$ & $14.5 \mathrm{R}$ & $15 \mathrm{R}$ & $15.5 \mathrm{R}$ & $16 \mathrm{R}$ & $16.5 \mathrm{R}$ & $17 \mathrm{R}$ & $17.5 \mathrm{R}$ & $18 \mathrm{R}$ & $18.5 \mathrm{R}$ & $19 \mathrm{R}$ & $19.5 \mathrm{R}$ & $20 \mathrm{R}$ \\
\hline \hline $5 \mathrm{U}$ & & & & & & & & & & & & & & & \\
\hline $4.5 \mathrm{U}$ & & & & & & & & & & & & & & & \\
\hline $4 \mathrm{U}$ & & 30 & 26 & 30 & 36 & 35 & 31 & 29 & 27 & 26 & 23 & 23 & 24 & 25 & 21 \\
\hline $3.5 \mathrm{U}$ & 39 & 38 & 37 & 43 & 46 & 46 & 44 & 44 & 43 & 33 & 33 & 31 & 32 & 31 & 28 \\
\hline $3 \mathrm{U}$ & & 35 & & 36 & 40 & 45 & 43 & 44 & 42 & 46 & 38 & 36 & 34 & 35 & 23 \\
\hline $2.5 \mathrm{U}$ & 59 & 60 & 50 & 42 & & 35 & & 32 & 31 & 33 & 36 & 32 & 30 & 27 & \\
\hline $2 \mathrm{U}$ & 75 & 66 & 64 & 62 & 57 & 59 & 51 & 45 & 46 & 45 & & & 32 & 29 & \\
\hline $1.5 \mathrm{U}$ & 84 & 87 & 84 & 80 & 68 & 56 & 50 & 48 & & 43 & & & & & \\
\hline $1 \mathrm{U}$ & & & & & & & & & & & & & & & \\
\hline $0.5 \mathrm{U}$ & & & & & & & & & & & & & & & \\
\hline
\end{tabular}




\section{OBSERVATION ANGLE CONSIDERATIONS}

\section{Sensitivity of retroreflective materials to observation angle}

The efficiency of retroreflective traffic signs depends on several angles, with the most important being the observation angle (the angle between the headlamp, traffic sign, and the eyes of the observer). In general, as the observation angle increases, the amount of light that is returned to the eyes of the observer decreases. A typical sensitivity profile for one common type of retroreflective material-encapsulated lens-is shown in Table 4. (Different types of retroreflective materials exhibit different profiles of sensitivity, some having steeper dropoffs with increased observation angle, while others having shallower dropoffs.) The sensitivity data in Table 4 is presented in a normalized form, by setting the amount of reflected light for an observation angle of $0.1^{\circ}$ to 1 .

The sensitivity of the material to observation angle is important for the present purpose, because the observation angle (for a given sign at a given distance) is influenced by the separation between the lamp and the eyes of the observer. Specifically, the closer the lamp is to the eyes, the smaller the observation angle. Consequently, the light from a lamp that is closer to the eyes is more effective (for retroreflective materials) than the light from a lamp further away. 
Table 4

Relative reflectance as a function of observation angle for encapsulated lens material at an entrance angle of $-4^{\circ}$.

The amount of the reflected light for an observation angle of $0.1^{\circ}$ was set to 1 . (Adapted from Sivak, Flannagan, and Gellatly, 1991.)

\begin{tabular}{|c|c|}
\hline Observation angle in degrees & Relative reflectance \\
\hline 0.10 & 1.000 \\
\hline 0.15 & 0.946 \\
\hline 0.20 & 0.875 \\
\hline 0.25 & 0.792 \\
\hline 0.30 & 0.699 \\
\hline 0.35 & 0.604 \\
\hline 0.40 & 0.509 \\
\hline 0.45 & 0.420 \\
\hline 0.50 & 0.340 \\
\hline 0.55 & 0.269 \\
\hline 0.60 & 0.211 \\
\hline 0.65 & 0.165 \\
\hline 0.70 & 0.131 \\
\hline 0.75 & 0.107 \\
\hline 0.80 & 0.091 \\
\hline 0.85 & 0.082 \\
\hline 0.90 & 0.077 \\
\hline
\end{tabular}




\section{Observation angles for headlamps, parking lamps, and auxiliary lamps}

By way of illustration, we calculated observation angles for

- $\quad$ signs in two locations (on the right shoulder and center overhead; see Figure 1 on page 2),

- $\quad$ four viewing distances $(75,100,125$, and $150 \mathrm{~m})$, and

- $\quad$ seven lamp locations (left and right headlamps, left and right parking lamps mounted either outboard or inboard of headlamps, and an auxiliary lamp mounted on the roof just above the driver; see Table 5).

Longer distances than those selected would lead to smaller observation angles and smaller differences among the lamps; shorter distances would lead to greater observation angles and more differences among the lamps. The headlamp locations are the marketweighted data from Sivak et al. (1996). We selected the parking lamps to be at the same mounting height as the headlamps, and offset $14 \mathrm{~cm}$ (center to center) either outboard or inboard of the headlamps.

Table 5

The locations of the lamps. The entries are in meters.

\begin{tabular}{|l|c|c|c|c|}
\hline \multirow{2}{*}{ Dimension } & \multirow{2}{*}{ Headlamps } & \multicolumn{2}{c|}{ Parking lamps } & Roof-mounted \\
\cline { 3 - 4 } & & Outboard & Inboard & \\
\hline Vertical to ground & 0.62 & 0.62 & 0.62 & 1.37 \\
\hline Lateral to the centerline of the vehicle & 0.56 & 0.70 & 0.42 & 0.35 \\
\hline Longitudinal to the front of the bumper & 0.20 & 0.20 & 0.20 & 2.34 \\
\hline
\end{tabular}


The driver eye position was based on the market-weighted data from Sivak, Flannagan, Budnik, Flannagan, and Kojima (1996). That position is given in Table 6. As an example, the calculated observation angles for one viewing distance $(100 \mathrm{~m})$ are listed in Table 7.

Table 6

The location of the driver eye point. The entries are in meters. (From Sivak, Flannagan, Budnik, Flannagan, and Kojima, 1996.)

\begin{tabular}{|l|c|}
\hline \multicolumn{1}{|c|}{ Dimension } & Distance \\
\hline Vertical to ground & 1.11 \\
\hline Lateral to the centerline of the vehicle & 0.35 \\
\hline Longitudinal to the front of the bumper & 2.34 \\
\hline
\end{tabular}

Table 7

The observation angles for two of the traffic signs in Figure 2 at a distance of $100 \mathrm{~m}$, by lamp location and sign location. The entries are in degrees.

\begin{tabular}{|l|c|c|}
\hline \multirow{2}{*}{ Lamp } & \multicolumn{2}{|c|}{ Location } \\
\cline { 2 - 3 } & Center overhead & Right shoulder \\
\hline Left headlamp & 0.36 & 0.35 \\
\hline Right headlamp & 0.62 & 0.53 \\
\hline Left parking lamp, outboard & 0.40 & 0.40 \\
\hline Right parking lamp, outboard & 0.69 & 0.60 \\
\hline Left parking lamp, inboard & 0.34 & 0.32 \\
\hline Right parking lamp, inboard & 0.55 & 0.47 \\
\hline Roof-mounted lamp & 0.15 & 0.15 \\
\hline
\end{tabular}




\section{Relative retroreflectance and relative efficiencies}

The derived observation angles were used to calculate the relative retroreflectances, using the relationship between observation angles and retroreflectances described in Table 4. As an example, Table 8 presents the relative retroreflectances for one viewing distance $(100 \mathrm{~m})$.

Using relative retroreflectances for each individual lamp, such as those shown in Table 8, we calculated the relative efficiency of a combined set of the left and the right parking lamp versus a combined set of both headlamps (separately for the outboard and inboard parking lamps), as well as the relative efficiency of a roof-mounted lamp versus a combined set of both headlamps. The following is an example of the calculations for the inboard parking lamps versus the headlamps for the right shoulder-mounted sign at $100 \mathrm{~m}$. In the first step, we calculated the sum of the relative reflectances for each inboard parking lamp $(0.67+0.40=1.07)$, and the corresponding sum for each headlamp $(0.60+0.30=$ 0.90). The next step involved computing the ratio of these two sums $(1.07 / 0.90=1.19)$. Finally, this ratio minus 1, multiplied by 100 ((1.19 - 1) x 100), gives us the relative efficiency of the inboard parking lamps versus the headlamps $(+19 \%)$. Tables 9 and 10 show the resulting relative efficiencies for both signs and all four viewing distances.

Table 8

The relative retroreflectances for two of the traffic signs in Figure 2 at a distance of $100 \mathrm{~m}$, by lamp location and sign location. (The retroreflectance at an observation angle of $0.1^{\circ}$ is set to 1.00.)

\begin{tabular}{|l|c|c|}
\hline \multirow{2}{*}{\multicolumn{1}{|c|}{ Lamp }} & \multicolumn{2}{c|}{ Location } \\
\cline { 2 - 3 } & Center overhead & Right shoulder \\
\hline \hline Left headlamp & 0.58 & 0.60 \\
\hline Right headlamp & 0.19 & 0.30 \\
\hline Left parking lamp, outboard & 0.52 & 0.50 \\
\hline Right parking lamp, outboard & 0.14 & 0.21 \\
\hline Left parking lamp, inboard & 0.62 & 0.67 \\
\hline Right parking lamp, inboard & 0.27 & 0.40 \\
\hline Roof-mounted lamp & 0.95 & 0.95 \\
\hline
\end{tabular}


Table 9

Relative efficiency (in \%) of lamp locations for a center overhead sign.

\begin{tabular}{|l|c|c|c|c|}
\hline \multirow{2}{*}{ Relative retroreflectance } & \multicolumn{4}{c|}{ Distance } \\
\cline { 2 - 5 } & $75 \mathrm{~m}$ & $100 \mathrm{~m}$ & $125 \mathrm{~m}$ & $150 \mathrm{~m}$ \\
\hline \hline Outboard parking lamps vs. headlamps & -18 & -15 & -12 & -9 \\
\hline Inboard parking lamps vs. headlamps & +14 & +14 & +11 & +8 \\
\hline Roof-mounted lamp vs. headlamp & +327 & +147 & +81 & +51 \\
\hline
\end{tabular}

Table 10

Relative efficiency (in \%) of lamp locations for a right shoulder-mounted sign.

\begin{tabular}{|l|c|c|c|c|}
\hline \multirow{2}{*}{ Relative retroreflectance } & \multicolumn{4}{c|}{ Distance } \\
\cline { 2 - 5 } & $75 \mathrm{~m}$ & $100 \mathrm{~m}$ & $125 \mathrm{~m}$ & $150 \mathrm{~m}$ \\
\hline \hline Outboard parking lamps vs. headlamps & -28 & -20 & -14 & -10 \\
\hline Inboard parking lamps vs. headlamps & +33 & +19 & +12 & +9 \\
\hline Roof-mounted lamp vs. headlamp & +260 & +113 & +65 & +42 \\
\hline
\end{tabular}

The information in Tables 9 and 10 indicates that the relative efficiencies of lamp locations depend on the sign location and on the viewing distance. For all conditions examined, outboard-mounted parking lamps are slightly less efficient than headlamps. For example, for the right shoulder-mounted sign at $100 \mathrm{~m}$, the outboard parking lamps are $20 \%$ less efficient than are the headlamps. On the other hand, the inboard-mounted parking lamps are slightly more efficient than the headlamps. For example, for the right shouldermounted sign at $100 \mathrm{~m}$, the inboard parking lamps are $19 \%$ more efficient than are the headlamps. Turning to the roof-mounted lamp, the information in Tables 9 and 10 indicates that a lamp mounted just above the driver is substantially more efficient than are the headlamps, especially at near distances. The largest difference in efficiency (an increase of $327 \%$ ) was obtained for the center overhead sign at $75 \mathrm{~m}$. 


\section{CONCLUSIONS}

\section{Light output of VOA lamps}

Relative to the conventional U.S. low beams, the first generation of the VOA low beams tends to produce less light in certain parts of the beam pattern that are relevant to the efficiency of retrorefective traffic signs. In the area just above the horizontal and to the right of the vertical this deficit exceeds $1,000 \mathrm{~cd}$ per lamp.

\section{Parking lamps}

Can parking lamps supplement the VOA lamps to maintain the status quo of light above the horizontal? Two considerations lead to the conclusion that parking lamps will not be able to fill the gap. First, the current U.S. requirements limit the output of parking lamps above the horizontal to no more than $125 \mathrm{~cd}$ (FMVSS, 1999). Second, the retroreflective geometry of parking lamps (i.e., the resultant observation angle) either provides no advantage (for parking lamps mounted outboard of headlamps) or provides only a marginal advantage (for parking lamps mounted inboard of headlamps).

\section{Roof-mounted auxiliary lamps}

A lamp mounted on the roof just above the driver would provide an advantage over the headlamps in terms of retroreflective geometry, because the observation angles for such a lamp would be smaller than for either headlamp. However, this advantage of a roofmounted lamp is affected somewhat by sign position (compare Tables 9 and 10), and affected greatly by viewing distance, with the advantage increasing with decreasing distance (see Tables 9 and 10). Consequently, it would be difficult, if not impossible, to design a beam pattern for a roof-mounted auxiliary lamp that, in combination with the VOA lamps, would have the same net effect as the conventional U.S. low beams for all signs at all distances. On the other hand, it should be possible to concentrate on the main areas of deficit of the VOA lamps, and to design the auxiliary lamps to assist the VOA lamps in these areas. Following this reasoning, the peak deficit vis-a-vis the conventional lamps is in the same general area for both the VOL lamps $\left(0.5^{\circ}\right.$ up, $2^{\circ}$ right $)$ and the VOR lamps $\left(0.5^{\circ}\right.$ up, $2.5^{\circ}$ right). Although a particular angular location can correspond to several combinations of sign position, road geometry, and distance, the area of the greatest deficit of the VOA lamps is most relevant for right shoulder-mounted signs. For example, a right shoulder-mounted sign (see Figure 1) at a distance of $150 \mathrm{~m}$ (a reasonable distance for sign 
legibility) would be at $0.57^{\circ}$ up and $2.13^{\circ}$ right for the right headlamp, and at $0.57^{\circ}$ up and $2.56^{\circ}$ right for the left headlamp. (For comparison, the corresponding angles for a roofmounted lamp, just above the driver, are $0.28^{\circ}$ up and $2.48^{\circ}$ right.) Because the angular differences among the lamps are rather small, in the following sample calculations we disregarded them. (Coincidentally, after rounding, the right shoulder-mounted sign at 150 $\mathrm{m}$ is at the location of the peak deficit of the VOL lamps in relation to the right headlamp $\left[0.5^{\circ}\right.$ up, $2^{\circ}$ right $]$, and at the location of the peak deficit of the VOR lamps in relation to the left headlamp $\left[0.5^{\circ}\right.$ up, $2.5^{\circ}$ right $]$.)

The relative advantage in efficiency of a roof-mounted lamp, in comparison to the headlamps, for a right shoulder-mounted sign at $150 \mathrm{~m}$ is about $42 \%$ (see Table 10). The peak deficits for the VOA lamps (see Tables 2 and 3) are 1,400 cd for the average VOL lamp (at $0.5^{\circ}$ up and $2.0^{\circ}$ right), and $1,036 \mathrm{~cd}$ for the average VOR lamp (at $0.5^{\circ}$ up and $2.5^{\circ}$ right). To make up the deficits for two headlamps $(2,800 \mathrm{~cd}$ for two VOL lamps and 2,072 cd for two VOR lamps), a single roof-mounted auxiliary lamp would need to deliver (after rounding) about 2,000 $\mathrm{cd}(2,800 / 1.42)$ for the VOL lamps and about 1,500 $\mathrm{cd} \mathrm{(2,072/1.42)}$ for the VOR lamps.

Following the above examples for the largest intensity deficits, analogous calculations could, in principle, be performed to generate a prescription for the complete beam pattern that a roof-mounted lamp would need to have to fully complement the VOL lamps, and another prescription to complement the VOR lamps. Such beam patterns would be expected to have minimum intensity requirements above the horizontal only, and the requirements would taper off as the lateral and vertical angles increased from the location of the peak intensity (near $0.5^{\circ}$ up and $2^{\circ}$ right). 


\section{REFERENCES}

Damasky (1995). Lichttechnische Entwincklung von Anforderungen an KraftfahrzeuhScheinwerfer (Dissertation). Darmstadt, Germany: Technical University of Darmstadt.

FMVSS (Federal Motor Vehicle Safety Standards). (1997). Standard No. 108: Lamps, reflective devices, and associated equipment. In Code of Federal Regulations, [Title] 49, Part 571. Washington, D.C. Office of the Federal Register.

FMVSS (Federal Motor Vehicle Safety Standards). (1999). Standard No. 108: Lamps, reflective devices, and associated equipment. In Code of Federal Regulations, [Title] 49, Part 571. Washington, D.C. Office of the Federal Register.

Huey, R., Decker, D., and Lyons, R. (1994). Driver perception of just-noticeable differences of automotive signal lamp intensities (Report No. DOT HS 808 209). Washington, D.C.: National Highway Traffic Safety Administration.

Sayer, J.R., Flannagan, M.J., Sivak, M., Kojima, S., and Flannagan, C.C. (1997). Just noticeable differences for low-beam headlamp intensities (Report No. UMTRI-974). Ann Arbor: The University of Michigan Transportation Research Institute.

Sivak, M., Flannagan, M.J., Budnik, E.A., Flannagan, C.C., and Kojima, S. (1996). The locations of headlamps and driver eye positions in vehicles sold in the U.S. (Report No. UMTRI-96-36). Ann Arbor: The University of Michigan Transportation Research Institute.

Sivak, M., Flannagan, M.J., and Gellatly, A.W. (1991). The influence of truck driver eye position on the effectiveness of retroreflective traffic signs (Report No. UMTRI-9135). Ann Arbor: The University of Michigan Transportation Research Institute.

Sivak, M., Flannagan, M.J., Kojima, S., and Traube, E.C. (1997). A market-weighted description of low-beam headlighting patterns in the U.S. (Report No. UMTRI-9737). Ann Arbor: The University of Michigan Transportation Research Institute.

Sivak, M., Gellatly, A.W., and Flannagan, M.J. (1991). Minimum light above horizontal of low-beam headlamps for nighttime legibility of traffic signs (Report No. UMTRI91-3). Ann Arbor: The University of Michigan Transportation Research Institute. 